Neil A. Busis, MD

Tait D. Shanafelt, MD

Christopher M. Keran, BA

Kerry H. Levin, MD

Heidi B. Schwarz, MD

Jennifer R. Molano, MD

Thomas R. Vidic, MD

Joseph S. Kass, MD, JD

Janis M. Miyasaki, MD

Jeff A. Sloan, PhD

Terrence L. Cascino, MD

Correspondence to

Dr. Busis:

busisna@upmc.edu

Editorial, page 726

Supplemental data at Neurology.org

\title{
Burnout, career satisfaction, and well-being among US neurologists in 2016
}

[a]

\section{ABSTRACT}

Objective: To study prevalence of and factors that contribute to burnout, career satisfaction, and well-being in US neurologists.

Methods: A total of 4,127 US American Academy of Neurology member neurologists who had finished training were surveyed using validated measures of burnout, career satisfaction, and well-being from January 19 to March 21, 2016.

Results: Response rate was $40.5 \%$ (1,671 of 4,127). Average age of participants was 51 years, with $65.3 \%$ male and nearly equal representation across US geographic regions. Approximately $60 \%$ of respondents had at least one symptom of burnout. Hours worked/week, nights on call/ week, number of outpatients seen/week, and amount of clerical work were associated with greater burnout risk. Effective support staff, job autonomy, meaningful work, age, and subspecializing in epilepsy were associated with lower risk. Academic practice (AP) neurologists had a lower burnout rate and higher rates of career satisfaction and quality of life than clinical practice (CP) neurologists. Some factors contributing to burnout were shared between AP and CP, but some risks were unique to practice setting. Factors independently associated with profession satisfaction included meaningfulness of work, job autonomy, effectiveness of support staff, age, practicing sleep medicine (inverse relationship), and percent time in clinical practice (inverse relationship). Burnout was strongly associated with decreased career satisfaction.

Conclusions: Burnout is common in all neurology practice settings and subspecialties. The largest driver of career satisfaction is the meaning neurologists find in their work. The results from this survey will inform approaches needed to reduce burnout and promote career satisfaction and well-being in US neurologists. Neurology ${ }^{\circledR} 2017 ; 88: 797-808$

\section{GLOSSARY}

AAN = American Academy of Neurology; $\mathbf{A P}=$ academic practice; $\mathbf{C P}=$ clinical practice; $\mathbf{M B I}$-HSS $=$ Maslach Burnout Inventory-Human Services Survey; QOL = quality of life.

Improving patient care and population health while reducing health care costs is critically dependent on timely access to care and optimal performance of health care providers. Physician burnout, career dissatisfaction, and lack of well-being threaten meaningful health care transformation. ${ }^{1,2}$

Well-being is a multidimensional construct that encompasses the complex interplay of an individual's mental, emotional, and physical health including positive aspects such as career satisfaction and negative aspects such as presence of burnout and dissatisfaction with work-life balance. ${ }^{1,3}$

Physician burnout comprises 3 dimensions: emotional exhaustion, feelings of cynicism and detachment (depersonalization), and a sense of ineffectiveness at work (low personal accomplishment). ${ }^{4}$ Burned out physicians may have impaired clinical judgment and lack empathy, leading to poor patient care and satisfaction..$^{3,5,6}$ The physician workforce may shrink, due to fewer entering and more leaving the field or physicians cutting back their clinical workload. ${ }^{7-10}$ Burned

\footnotetext{
From the Department of Neurology (N.A.B.), University of Pittsburgh School of Medicine, PA; Division of Hematology (T.D.S.), Division of Biomedical Statistics and Informatics (J.A.S.), and Department of Neurology (T.L.C.), Mayo Clinic, Rochester, MN; Member Insights Department (C.M.K.), American Academy of Neurology, Minneapolis, MN; Department of Neurology (K.H.L.), Cleveland Clinic, OH; Department of Neurology (H.B.S.), University of Rochester Medical Center, NY; Department of Neurology and Rehabilitation (J.R.M.), University of Cincinnati, OH; Department of Neurology (T.R.V.), Elkhart Clinic, IN; Department of Neurology (J.S.K.), Baylor College of Medicine, Houston, TX; and Alberta Health Services Medicine (J.M.M.), University of Alberta, Canada.

Go to Neurology.org for full disclosures. Funding information and disclosures deemed relevant by the authors, if any, are provided at the end of the article.
} 
out physicians negatively influence their colleagues and are more likely to have work-life imbalance, work-home conflicts, and health problems including substance abuse, depression, and suicide. ${ }^{11-17}$

Burnout and depression, while sharing some features such as emotional exhaustion, are separate entities. ${ }^{18}$ Burnout is situationallyspecific while depression is context-free. ${ }^{18} \mathrm{Six}$ main domains are associated with increased burnout risk: workload, control, reward, community, fairness, and values. ${ }^{18}$ Interventions to reduce the risk of and mitigate burnout have mainly centered on personal wellness strategies; however, determinants at the levels of the work unit, organization, and nation play a primary role. ${ }^{18}$ Little research has evaluated the efficacy of burnout risk reduction and mitigation efforts. ${ }^{18}$

Burnout is more prevalent among physicians than the general US workforce and is common in all medical and surgical specialties and practice settings. ${ }^{13,19}$ Burnout and satisfaction with work-life balance in US physicians worsened between 2011 and 2014, at which time over half of US physicians met burnout criteria. $^{19}$

Burnout rates vary by specialty. Neurology is one of the few specialties with both high rates of burnout and low satisfaction with work-life balance. ${ }^{13,19,20}$ In 2013, the American Academy of Neurology (AAN) Workforce Task Force found demand for neurologist services exceeded supply in most states. ${ }^{21}$ By 2025 , demand for neurologists will be even higher. ${ }^{21}$ Given relationships between workload and burnout and burnout and professional work effort, ${ }^{7-10}$ the high rate of neurologist burnout may contribute to and be exacerbated by this shortage.

Recognizing this crisis, ${ }^{20,22}$ the AAN formed a task force to study neurologist burnout, career satisfaction, and work-life balance; determine associated factors; and develop and disseminate evidence-based resources to mitigate burnout and enhance career satisfaction. We report the results of a national survey of practicing US neurologists characterizing professional burnout, career satisfaction, and well-being.

METHODS Study population. The population of interest included neurologists and neurology trainees who were current members of the AAN and had a primary address in the United
States $(\mathrm{n}=17,413)$. Among the 17,413 members meeting these criteria, 7,852 were excluded because they were missing AAN member record data (postal address, e-mail address, sex, birth date, or subspecialty), received surveys from the AAN within the last 6 months, or were involved with the study, leaving an eligible population of 9,561 .

Attempting to yield a margin of error no more than $\pm 3.0 \%$ assuming a $20 \%$ response rate, a simple random sample of 5,000 members was selected from the eligible population of 9,561. We also oversampled all who had a primary subspecialty of neurohospitalist $(\mathrm{n}=41)$ and endovascular and interventional neurology $(n=24)$ because of their low numbers and unique practice settings, resulting in 5,065 members in the sample. This sample included neurologists $(\mathrm{n}=4,127)$ as well as residents and fellows ( $n=938$ ). The present analysis focuses on the 4,127 neurologists who had completed training.

Sample members were mailed a survey on January 19, 2016, an e-mail with a link to an online survey, and a fax (if available) with a link to an online survey. Nonrespondents received up to 2 additional mailings and faxes and up to 5 additional e-mail reminders. All communications mentioned their eligibility in a drawing for 1 of $20 \$ 500$ Visa gift cards. All communications and data collection were conducted on behalf of the AAN by Anderson, Niebuhr \& Associates, Inc. (Minneapolis, MN), which provided the AAN with de-identified (anonymized) data from those who completed their survey by March 21, 2016.

Standard protocol approvals, registrations, and patient consents. Completing the survey was implied consent to participate in the study. After the anonymized data were provided to the AAN, the study was reviewed and granted exempt status by the University of Pittsburgh institutional review board.

Study measures. The survey (available at Neurology.org) consisted of 57 questions covering personal and professional characteristics with previously validated instruments to measure burnout and career satisfaction ${ }^{4,13,19}$ and included a free text entry area at the end.

Burnout was measured using the 22-item Maslach Burnout Inventory-Human Services Survey (MBI-HSS). The MBI-HSS has 3 subscales to evaluate each domain of burnout: emotional exhaustion, depersonalization, and personal accomplishment. ${ }^{4}$ Using the standard scoring criteria for health care workers, and in keeping with previous studies and convention, ${ }^{13,19,23}$ we considered neurologists with high scores on the emotional exhaustion $(\geq 27)$ or depersonalization $(\geq 10)$ subscales as having at least one manifestation of professional burnout. Career satisfaction was assessed using 2 questions from previous physician surveys regarding career and specialty choice. ${ }^{13,19,24-26}$ Questions from the Empowerment at Work ${ }^{19,27}$ and Physician Job Satisfaction ${ }^{28}$ scales explored meaning in work and professional satisfaction. Two questions were asked about the amount of time spent on clerical tasks directly and indirectly related to patient care. ${ }^{29}$

Statistical analysis. Missing data for 4 demographic variables (ranging from 5\% to $8 \%$ missing data) were replaced with data from the AAN membership data file (accuracy from $96.5 \%$ to $99.6 \%$, based on correct match between nonmissing survey responses and the AAN membership data file): year of birth, sex, state, and career stage (in or out of training).

Standard descriptive statistics were used to characterize responding neurologists. With 1,671 responses to the survey, the percentage estimates were accurate to $\pm 2.2 \%$ with $95 \%$ confidence. Associations between variables were evaluated using the $\chi^{2}$ test for categorical variables and the Kruskal-Wallis test for continuous variables. All tests were 2 -sided with type I error rates $(\alpha)$ 
Table 1 Personal and practice characteristics for academic practice (AP) vs clinical practice (CP)

\begin{tabular}{|c|c|c|c|c|}
\hline & All $(n=1,671)$ & $A P(n=529)$ & $\mathrm{CP}^{\mathrm{a}}(\mathrm{n}=959)$ & $\begin{array}{l}\text { p Value } \\
\text { comparison AP to } \mathrm{CP}^{\mathrm{b}}\end{array}$ \\
\hline \multicolumn{5}{|l|}{ Personal characteristics } \\
\hline \multicolumn{5}{|l|}{ Age, y } \\
\hline Mean & 52 & 50 & 53 & $<0.001$ \\
\hline Median & 51 & 48 & 53 & \\
\hline SD & 12 & 12 & 12 & \\
\hline Missing, $\mathrm{n}$ & 0 & 0 & 0 & \\
\hline Age $\%$ in categories $<40$ & 20.2 & 24.6 & $17.4^{\mathrm{c}}$ & 0.001 \\
\hline $40-49$ & 25.4 & 27.4 & 24.9 & \\
\hline $50-59$ & 25.9 & 24.2 & 26.9 & \\
\hline $60-69$ & 20.5 & 16.1 & $23.3^{c}$ & \\
\hline $70+$ & 8.0 & 7.8 & 7.5 & \\
\hline Sex, \% & & & & 0.003 \\
\hline Male & 65.3 & 60.7 & $68.3^{c}$ & \\
\hline Female & 34.7 & 39.3 & $31.7^{c}$ & \\
\hline Missing, $n$ & 0 & 0 & 0 & \\
\hline \multicolumn{5}{|l|}{ Geographic region, ${ }^{d} \%$} \\
\hline Northeast & 23.0 & 28.7 & $20.0^{c}$ & 0.001 \\
\hline Midwest & 24.1 & 24.4 & 24.5 & \\
\hline South & 30.4 & 29.7 & 30.9 & \\
\hline West & 21.9 & 16.8 & $23.9^{c}$ & \\
\hline$A E, P R, V I$ & 0.7 & 0.4 & 0.7 & \\
\hline Missing, $n$ & 0 & 0 & 0 & \\
\hline \multicolumn{5}{|l|}{ Practice characteristics } \\
\hline \multicolumn{5}{|l|}{ Primary work setting, ${ }^{e} \%$} \\
\hline Solo practice & 14.3 & 0.0 & 23.5 & \\
\hline Neurology group & 19.5 & 0.0 & 31.9 & \\
\hline Multispecialty group & 13.6 & 0.0 & 22.3 & \\
\hline Academic-based & 33.7 & 100.0 & 0.0 & \\
\hline Hospital-based & 13.6 & 0.0 & 22.3 & \\
\hline Government-based & 3.2 & 0.0 & 0.0 & \\
\hline Other & 2.2 & 0.0 & 0.0 & \\
\hline Missing, $n$ & 99 & 0 & 0 & \\
\hline \multicolumn{5}{|l|}{ Years in practice ${ }^{f}$} \\
\hline Mean & 17.3 & 15.6 & 18.1 & $<0.001$ \\
\hline Median & 16.0 & 12.5 & 17.0 & \\
\hline SD & 12.1 & 12.0 & 11.9 & \\
\hline Missing, $n$ & 76 & 6 & 7 & \\
\hline$\%$ In categories $<10$ & 32.7 & 39.2 & $29.1^{\mathrm{c}}$ & $<0.001$ \\
\hline $10-19$ & 24.1 & 24.1 & 24.8 & \\
\hline$>20$ & 43.1 & 36.7 & $46.1^{\mathrm{c}}$ & \\
\hline Employment status, \% & & & & $<0.001$ \\
\hline Employed at a hospital & 41.6 & 65.1 & $27.1^{\mathrm{c}}$ & \\
\hline Employed at a practice & 22.9 & 20.1 & $26.1^{\mathrm{c}}$ & \\
\hline Owner/partner & 26.8 & 0.4 & $44.1^{\mathrm{c}}$ & \\
\hline
\end{tabular}

Continued 


\begin{tabular}{|c|c|c|c|c|}
\hline & All $(n=1,671)$ & $\operatorname{AP}(n=529)$ & $C P^{a}(n=959)$ & $\begin{array}{l}\text { p Value } \\
\text { comparison AP to } \mathrm{CP}^{\mathrm{b}}\end{array}$ \\
\hline Other & 8.7 & 14.4 & $2.7^{c}$ & \\
\hline Missing, $\mathrm{n}$ & 68 & 2 & 4 & \\
\hline
\end{tabular}

a Includes solo practice, neurology group, multispecialty group, and hospital-based.

${ }^{b}$ Comparisons tested using Kruskal-Wallis for continuous variables and $\chi^{2}$ for categorical variables.

c This paired comparison ( $z$ test) was found to be significant at a $p<0.05$ level.

dRegional designations: Northeast: Connecticut, Massachusetts, Maine, New Hampshire, New Jersey, New York, Pennsylvania, Rhode Island, Vermont; Midwest: lowa, Illinois, Indiana, Kansas, Michigan, Minnesota, Missouri, Nebraska, North Dakota, Ohio, South Dakota, Wisconsin; South: Alabama, Arkansas, Washington, DC, Delaware, Florida, Georgia, Kentucky, Louisiana, Maryland, Mississippi, North Carolina, Oklahoma, South Carolina, Tennessee, Texas, Virginia, West Virginia; West: Alaska, Arizona, California, Colorado, Hawaii, Idaho, Montana, New Mexico, Nevada, Oregon, Utah, Washington, Wyoming; other: Armed Forces Europe (AE), Armed Forces Pacific, Guam, Puerto Rico (PR), Virgin Islands (VI).

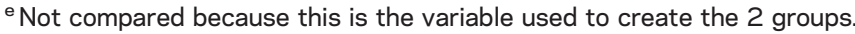

f Since completion of residency and fellowship training.

of 0.05 . Multivariable analyses to identify demographic and professional characteristics associated with the dependent outcomes were performed using binary logistic regression. All analyses were performed using IBM (Armonk, NY) SPSS Statistics version 23.

RESULTS Response rate and representativeness. Of the 4,127 neurologists surveyed, 1,671 responded (response rate $40.5 \%$ ). The representativeness of respondents differed from nonrespondents $(p<0.05)$ (table e-1), with overrepresentation from women $(+3.7 \%)$, midwest region $(+3.6 \%)$, and child neurologists $(+2.0 \%)$, and underrepresentation from men $(-3.7 \%)$, northeast region $(-3.2 \%)$, other work setting $(-3.0 \%)$, and subspecialties of vascular neurology and stroke $(-2.0 \%)$ and other $(-3.5 \%)$. Respondents and nonrespondents were similar for age $(p=0.100)$. Analysis of early responders (the $53.4 \%$ who responded within the first 19 days) to late responders (the $46.6 \%$ who responded over the next 41 days) found no significant differences for burnout, sex, age, region, and academic vs clinical practice (all $p>0.05$ ). Collectively, there was evidence that the sample was generally representative of US neurologists with respect to demographic characteristics and level of burnout.

Personal and practice characteristics. The median age of all participants was 51 years, $65.3 \%$ were men, and they were well-represented across geographic regions (table 1). Compared with neurologists in academic practice $(\mathrm{AP})$, neurologists in clinical practice $(\mathrm{CP})$ were older $(p<0.001)$, more likely to be male $(p=$ $0.003)$, less likely to be in the northeast region, and more likely to be in the west $(p=0.001)$. Respondents practiced neurology a mean of 17.3 years. One-third of neurologists $(33.7 \%)$ worked in AP. CP neurologists included those in solo practice (14.3\%), neurology group (19.5\%), multispecialty group (13.6\%), and hospital-based (13.6\%) settings. Government-based $(3.2 \%)$ and other $(2.2 \%)$ practices were excluded from $\mathrm{AP}$ vs $\mathrm{CP}$ comparisons.
Subspecialty and workload. Almost one-third of responders (table 2) identified themselves as general neurologists (31.9\%). The 3 most commonly identified subspecialties were epilepsy $(8.4 \%)$, child neurology (8.3\%), and movement disorders (7.4\%). Respondents reported working a mean of 55.7 hours per week, with approximately three-fourths (76.1\%; mean 42.4 hours/ week) spent in clinical care. The most common method of compensation was salary plus bonus (39.9\%), followed by straight salary $(32.0 \%)$, and pure production-based income (28.1\%).

Although AP neurologists worked more hours per week on average (58.1 vs $55.3, p<0.001$ ), they spent a smaller proportion of their time in direct patient care $(59.3 \%$ vs $87.6 \%, p<0.001)$ and devoted more time to research $(16.4 \%$ vs $1.7 \%, p<0.001)$, teaching (11.3\% vs $2.8 \%, p<0.001)$, and administration (11.9\% vs $6.5 \%, p<0.001)$. CP neurologists spent more nights per week on call (median 2 vs $1, p<$ 0.001 ), cared for more outpatients per week (52.3 vs $29.5, p<0.001$ ), and spent more weekends per year rounding in the hospital (11.3 vs 8.1, $p<0.001)$. Compared to $\mathrm{CP}$ neurologists, AP neurologists were more likely to get a straight salary $(42.9 \%$ vs $23.7 \%$, $p<0.05)$ or a salary plus bonus $(53.3 \%$ vs $32.8 \%$, $p<0.05)$ and rarely received a production-based income $(3.8 \%$ vs $43.6 \%, p<0.05)$.

Career satisfaction and burnout. Table 3 compares burnout, career satisfaction, and well-being among participating neurologists. A majority, $53.4 \%$, of neurologists (850 of 1,591) had high emotional exhaustion, $41.4 \%$ (664 of 1,603) high depersonalization, and $21.2 \%$ (334 of 1,573$)$ a low personal accomplishment score. Overall, 60.1\% (972 of 1,616) of neurologists had at least one symptom of burnout (high emotional exhaustion or high depersonalization). CP neurologists had a higher burnout rate than AP neurologists (63.3\% vs $55.7 \%, p=0.004)$, resulting from 
Table 2 Subspecialty and workload for academic practice (AP) vs clinical practice (CP)

\begin{tabular}{|c|c|c|c|c|}
\hline & All $(n=1,671)$ & $\operatorname{AP}(n=529)$ & $C P^{a}(n=959)$ & $\begin{array}{l}\mathrm{p} \text { Value } \\
\text { comparison } \\
\mathrm{AP} \text { to } C \mathrm{P}^{\mathrm{b}}\end{array}$ \\
\hline \multicolumn{5}{|l|}{ Subspecialty } \\
\hline Primary focus, $\%^{c}$ & & & & $<0.001$ \\
\hline General neurology & 31.9 & 7.6 & $45.8^{d}$ & \\
\hline Other & 9.8 & 12.0 & $7.4^{\mathrm{d}}$ & \\
\hline Epilepsy & 8.4 & 14.8 & $4.7^{\mathrm{d}}$ & \\
\hline Child neurology & 8.3 & 9.6 & 7.7 & \\
\hline Movement disorders & 7.4 & 13.3 & $3.6^{\mathrm{d}}$ & \\
\hline Vascular neurology and stroke & 6.6 & 8.5 & 5.6 & \\
\hline Neuromuscular medicine & 5.6 & 10.0 & $3.3^{\mathrm{d}}$ & \\
\hline Headache medicine & 3.9 & 4.4 & 3.8 & \\
\hline Neurohospitalist & 3.5 & 1.3 & $4.9^{d}$ & \\
\hline Sleep medicine & 3.4 & 2.8 & 3.7 & \\
\hline Behavioral neurology and neuropsychiatry & 3.0 & 5.0 & $1.8^{\mathrm{d}}$ & \\
\hline Clinical neurophysiology & 3.0 & 2.6 & 3.5 & \\
\hline Neuroimmunology and multiple sclerosis & 3.0 & 4.1 & 2.6 & \\
\hline Neurocritical care & 2.3 & 3.7 & $1.5^{\mathrm{d}}$ & \\
\hline Missing, $n$ & 344 & 71 & 178 & \\
\hline Compensation method, \% & & & & $<0.001$ \\
\hline Straight salary & 32.0 & 42.9 & $23.7^{d}$ & \\
\hline Salary plus bonus & 39.9 & 53.3 & $32.8^{d}$ & \\
\hline Production-based income & 28.1 & 3.8 & $43.6^{d}$ & \\
\hline Missing, $n$ & 73 & 4 & 13 & \\
\hline \multicolumn{5}{|l|}{ Workload } \\
\hline Hours worked per week & & & & $<0.001$ \\
\hline Mean & 55.7 & 58.1 & 55.3 & \\
\hline Median & 55.0 & 60.0 & 55.0 & \\
\hline SD & 16.3 & 14.4 & 16.9 & \\
\hline Missing, $n$ & 65 & 4 & 13 & \\
\hline$\%$ Time devoted to clinical practice & & & & $<0.001$ \\
\hline Mean & 76.1 & 59.3 & 87.6 & \\
\hline Median & 85.0 & 60.0 & 90.0 & \\
\hline SD & 24.8 & 23.9 & 15.2 & \\
\hline Missing, $n$ & 52 & 0 & 3 & \\
\hline$\%$ Time devoted to research & & & & $<0.001$ \\
\hline Mean & 7.4 & 16.4 & 1.7 & \\
\hline Median & 0.0 & 10.0 & 0.0 & \\
\hline SD & 16.2 & 20.6 & 5.8 & \\
\hline Missing, $n$ & 52 & 0 & 3 & \\
\hline$\%$ Time devoted to teaching & & & & $<0.001$ \\
\hline Mean & 5.9 & 11.3 & 2.8 & \\
\hline Median & 3.0 & 10.0 & 0.0 & \\
\hline SD & 8.9 & 11.1 & 5.4 & \\
\hline Missing, $n$ & 52 & 0 & 3 & \\
\hline
\end{tabular}


Table 2 Continued

\begin{tabular}{|c|c|c|c|c|}
\hline & All $(n=1,671)$ & $\mathrm{AP}(n=529)$ & $C P^{a}(n=959)$ & $\begin{array}{l}p \text { Value } \\
\text { comparison } \\
\text { AP to } C P^{b}\end{array}$ \\
\hline$\%$ Time devoted to administration & & & & $<0.001$ \\
\hline Mean & 8.8 & 11.9 & 6.5 & \\
\hline Median & 5.0 & 10.0 & 4.0 & \\
\hline SD & 12.6 & 13.6 & 9.9 & \\
\hline Missing, $n$ & 52 & 0 & 3 & \\
\hline$\%$ Time devoted to other & & & & 0.592 \\
\hline Mean & 1.8 & 1.1 & 1.3 & \\
\hline Median & 0.0 & 0.0 & 0.0 & \\
\hline SD & 9.5 & 5.9 & 6.0 & \\
\hline Missing, $n$ & 52 & 0 & 3 & \\
\hline Median nights on call/week & 1 & 1 & 2 & $<0.001$ \\
\hline Missing, $n$ & 83 & 13 & 17 & \\
\hline $\begin{array}{l}\text { Mean no. outpatients in clinic } \\
\text { per week }\end{array}$ & 42.7 & 29.5 & 52.3 & $<0.001$ \\
\hline Missing, $n$ & 69 & 5 & 10 & \\
\hline $\begin{array}{l}\text { Mean no. inpatients on average } \\
\text { hospital day }\end{array}$ & 6.3 & 7.2 & 6.1 & $<0.001$ \\
\hline Missing, $n$ & 72 & 8 & 10 & \\
\hline $\begin{array}{l}\text { Mean no. weekends rounded in } \\
\text { hospital }\end{array}$ & 9.9 & 8.1 & 11.3 & $<0.001$ \\
\hline Missing, $n$ & 66 & 5 & 7 & \\
\hline
\end{tabular}

${ }^{a}$ Includes solo practice, neurology group, multispecialty group, and hospital-based.

${ }^{b}$ Comparisons tested using Kruskal-Wallis for continuous variables and $\chi^{2}$ for categorical variables.

${ }^{\mathrm{c}}$ Primary foci with fewer than 30 cases (including endovascular and interventional neurology) were added to the other category.

${ }^{d}$ This paired comparison ( $z$ test) was found to be significant at a $p<0.05$ level.

higher scores in both emotional exhaustion $(p=$ $0.008)$ and depersonalization $(p=0.014)$. Personal accomplishment scores were similar in AP and $\mathrm{CP}$ groups $(p=0.764)$. Demographic and practice characteristics associated with burnout on univariate analysis are reported in tables e- 2 and e-3.

With respect to career satisfaction, $61.3 \%$ (995 of $1,622)$ of neurologists would choose to become a physician again while $67.2 \%(1,096$ of 1,631$)$ would choose to become a neurologist again. Career satisfaction scores differed between $\mathrm{CP}$ and $\mathrm{AP}$ neurologists, with more AP neurologists indicating they would choose to be both a physician $(p<0.001)$ and a neurologist $(p<0.001)$ again. Overall, $67.0 \%$ of neurologists were satisfied with their job, with no differences between $\mathrm{AP}$ and $\mathrm{CP}(p=0.434)$.

Median overall quality of life (QOL) of neurologists was 7 on a $0-10$ scale while the median score on the fatigue scale was 5 out of 10 . Scores less than 6 on the QOL scale are clinically meaningful ${ }^{30}: 34.2 \%$ of our respondents reported scores less than 6 . Only 1 in 3 neurologists (32.3\%: 523 of 1,620) indicated their work schedule left enough time for personal/ family life. AP neurologists scored higher for QOL $(p=0.033)$, but there was no difference (all $p>$ $0.05)$ in fatigue or work-life balance between AP and $\mathrm{CP}$ neurologists.

A majority of neurologists $(59.9 \%)$ reported that they have significant autonomy in determining how they do their job. Most neurologists (87.6\%) reported that their work is meaningful to them. There were no differences between $\mathrm{AP}$ and $\mathrm{CP}$ in these 2 measures ( $p=0.326$ and $p=0.517$, respectively).

A minority of neurologists indicated the amount of time spent on clerical tasks was reasonable, both directly (23.0\%: 369 of 1,607) and indirectly $(15.9 \%$ : 255 of 1,605$)$ related to patient care. A majority of neurologists (56.3\%: 900 of 1,598) indicated that they had too little support staff to assist them in their work. Satisfaction with clerical tasks was lower for AP compared to $\mathrm{CP}$ neurologists in direct $(p=$ $0.004)$ and indirect $(p=0.010)$ patient care tasks. AP neurologists were more likely to indicate that they lacked sufficient support staff $(p<0.001)$.

Factors associated with burnout. Multivariable analyses identified factors associated with burnout (table 4). In 
Table 3 Burnout and career satisfaction: academic practice (AP) vs clinical practice (CP)

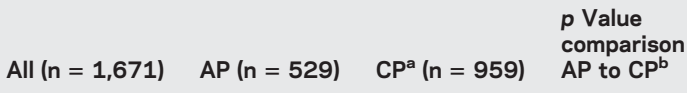

Burnout indices ${ }^{c}$

Emotional exhaustion ${ }^{d}$

Median

\% Low score

28.0

$\%$ Intermediate score

$\%$ High score

Missing, n

$$
27.3
$$

19.3

53.4

80

$P^{a}(n=959)$

Depersonalization ${ }^{d}$

Median

8.0

\% Low score

36.6

22.0

41.4

$\%$ High score

Missing, $\mathrm{n}$

68

26.5

29.0

0.008

30.2

$24.2^{\mathrm{e}}$

0.023

Personal accomplishment ${ }^{d}$

Median

$\%$ High score

40.0

19.8

19.1

50.0

$56.7^{\mathrm{e}}$

$\%$ Intermediate score

\% Low score

Missing, $n$

$\%$ Burned out $^{f}$

Missing, $n$

\section{2}

26.0

21.2

98

60.1

55

3

32

Career satisfaction

Would become physician again

(career choice), \% yes

Missing, $\mathrm{n}$

Would become neurologist again

(specialty choice), \% yes

Missing, $\mathrm{n}$

Overall, I am satisfied

with my job, \% agree

Missing, $\mathrm{n}$

Quality of life, fatigue, and work-life integration

Overall quality of life, ${ }^{9}$ mean (SD)

Median

Missing, $\mathrm{n}$

Level of fatigue, ${ }^{9}$ mean (SD)

Median

Missing, $\mathrm{n}$

Work schedule leaves enough time for

personal/family life, \% agree

Missing, $n$

Autonomy and meaning in work

I have significant autonomy in determining how I do my job, \% agree

Missing, $n$

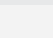

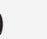

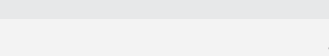

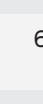

6

49

67.2

40

67.0

51

6.2 (2.2)

7.0

5

$5.2(2.4)$

5.0

9

32.3

51

59.9

46

$\begin{array}{ll}7.0 & 8.0 \\ 39.1 & 34.2 \\ 24.1 & 21.4 \\ 36.8 & 44.4^{e} \\ 2 & 18\end{array}$

0.014

0.018

4.4

18

$\begin{array}{lll}40.0 & 40.0 & 0.764\end{array}$

$\begin{array}{lll}53.4 & 52.1 & 0.895\end{array}$

$25.8 \quad 26.3$

$20.8 \quad 21.6$

$10 \quad 36$

$55.7 \quad 63.3$

0.004

1

11

67.4

57.5

$<0.001$

110

74.5

0

67.9

$\begin{array}{lll}0 & 7\end{array}$


Table 3 Continued

\begin{tabular}{|c|c|c|c|c|}
\hline & All $(n=1,671)$ & $\operatorname{AP}(n=529)$ & $\mathrm{CP}^{\mathrm{a}}(\mathrm{n}=959)$ & $\begin{array}{l}p \text { Value } \\
\text { comparison } \\
\mathrm{AP} \text { to } \mathrm{CP}^{\mathrm{b}}\end{array}$ \\
\hline The work I do is meaningful to me, $\%$ agree & 87.6 & 88.3 & 87.1 & 0.517 \\
\hline Missing, $n$ & 47 & 0 & 4 & \\
\hline \multicolumn{5}{|l|}{ Clerical tasks and support staff } \\
\hline $\begin{array}{l}\text { The amount of time I spend on clerical tasks directly } \\
\text { related to patient care is reasonable, } \% \text { agree }\end{array}$ & 23.0 & 18.3 & 24.8 & 0.004 \\
\hline Missing, $n$ & 64 & 4 & 5 & \\
\hline $\begin{array}{l}\text { The amount of time I spend on } \\
\text { clerical tasks indirectly related to patient care is } \\
\text { reasonable, \% agree }\end{array}$ & 15.9 & 12.2 & 17.2 & 0.010 \\
\hline Missing, $n$ & 66 & 4 & 7 & \\
\hline $\begin{array}{l}\text { How much effective support staff do you } \\
\text { have to assist you in your work? \% Too little }\end{array}$ & 56.3 & 67.9 & 49.1 & $<0.001$ \\
\hline Missing, $n$ & 73 & 0 & 25 & \\
\hline
\end{tabular}

${ }^{a}$ Includes solo practice, neurology group, multispecialty group, and hospital-based.

${ }^{\mathrm{b}}$ Comparisons tested using Kruskal-Wallis for continuous variables and $\chi^{2}$ for categorical variables.

${ }^{\mathrm{c}}$ As assessed using the full Maslach Burnout Inventory.

${ }^{d}$ Per the standard scoring of the Maslach Burnout Inventory for health care workers, physicians with scores on the emotional exhaustion subscale $\geq 27$, the depersonalization subscale $\geq 10$, or scores $\leq 33$ on the personal accomplishment subscale are considered to have a high degree of burnout in that dimension.

${ }^{\text {e }}$ Low scores on the Personal Accomplishment sub-scale are less favorable.

${ }^{f}$ High score on emotional exhaustion or depersonalization subscales of the Maslach Burnout Inventory (see Methods).

g Scale of $0=$ As bad as it can be to $10=$ As good as it can be.

${ }^{\mathrm{h}}$ For example, order entry, dictation, laboratory results review, communicating with patients via a patient portal.

'For example, correspondence, completion of forms, answering phone calls.

addition to a model for all neurologists, separate models were developed for AP and CP neurologists because of substantial differences in personal and professional characteristics of these groups. For all neurologists, increased hours worked per week $(p=$ $0.003)$, nights on call per week $(p=0.013)$, and number of outpatients $(p=0.024)$ were associated with higher burnout risk. Greater job autonomy $(p<$ 0.001), meaningful work $(p<0.001)$, reasonable amount of direct clerical tasks $(p<0.001)$, effective support staff $(p=0.001)$, older age of the neurologist $(p<0.001)$, and reporting a subspecialty in epilepsy compared to general neurology $(p=0.032)$ were associated with lower burnout risk.

Risk profiles differed by practice setting. For AP neurologists, burnout was associated with more hours worked per week $(p=0.006)$ and higher percentage of clinical time $(p=0.043)$, while greater job autonomy $(p<0.001)$ was associated with lower burnout risk. For CP neurologists, burnout was associated with increased number of outpatients seen per week $(p=0.004)$, while greater job autonomy $(p<0.001)$, meaning in work $(p=$ $0.001)$, reasonable amount of direct clerical tasks $(p=0.002)$, effective support staff $(p=0.001)$, older age $(p<0.001)$, and epilepsy subspecialization compared to general neurology $(p=0.05)$ were associated with lower burnout risk.
Factors associated with profession satisfaction. Multivariable analyses identified factors associated with profession satisfaction (table 5). Neurologists were 3 times more likely to be satisfied in their profession if they indicated that their work was meaningful $(p<0.001)$ and 2 times more likely to have profession satisfaction if they reported job autonomy $(p<0.001)$. Effective support staff $(p=0.020)$ and older age $(p<0.001)$ were also associated with profession satisfaction. Respondents meeting criteria for burnout were $64.3 \%$ less likely to have profession satisfaction $(p<0.001)$. Practicing sleep medicine was associated with $70 \%$ less profession satisfaction compared to general neurology $(p=0.002)$. Each one-unit increase of percent time in clinical practice was associated with $1 \%$ less profession satisfaction $(p=0.005)$.

DISCUSSION Our study evaluating burnout, career satisfaction, and well-being of US neurologists used instruments previously validated in studies of other medical specialties. At the time of our survey, approximately $60 \%$ of neurologists had at least one symptom of burnout, confirming earlier studies of smaller numbers of neurologists. ${ }^{13,19}$

Previous studies showed that burnout prevalence, career dissatisfaction, and work-life imbalance are higher among neurologists than physicians in most other specialties. ${ }^{13,19}$ Our study confirms these findings 


\begin{tabular}{|c|c|c|c|c|c|}
\hline Group & Predictor & OR & \multicolumn{2}{|c|}{$95 \% \mathrm{Cl}$} & p Value \\
\hline \multirow[t]{7}{*}{ All neurologists ${ }^{a-d}$} & Autonomy in job (Q9a) (0 = disagree/neutral, $1=$ agree) & 0.325 & 0.237 & 0.446 & $<0.001$ \\
\hline & Meaningful work (Q9b) (0 = disagree/neutral, 1 = agree) & 0.334 & 0.188 & 0.593 & $<0.001$ \\
\hline & $\begin{array}{l}\text { Reasonable amount of direct clerical tasks (Q10a) } \\
(0=\text { disagree/neutral, } 1=\text { agree })\end{array}$ & 0.498 & 0.340 & 0.731 & $<0.001$ \\
\hline & Hours worked per week (Q12) & 1.016 & 1.005 & 1.027 & 0.003 \\
\hline & Nights on call per week (Q14) & 1.092 & 1.019 & 1.171 & 0.013 \\
\hline & No. of outpatients (Q15) & 1.007 & 1.001 & 1.013 & 0.024 \\
\hline & Age (Q19) & 0.973 & 0.960 & 0.985 & $<0.001$ \\
\hline Academic practice $e^{a, b, e, f}$ & \% Clinical time (Q13_1) & 1.016 & 1.000 & 1.032 & 0.043 \\
\hline \multirow[t]{7}{*}{ Clinical practice $^{\mathrm{a}, \mathrm{b}, \mathrm{g}, \mathrm{h}}$} & Autonomy in job (Q9a) (0 = disagree/neutral, 1 = agree) & 0.299 & 0.195 & 0.457 & $<0.001$ \\
\hline & Meaningful work (Q9b) (0 = disagree/neutral, 1 = agree) & 0.264 & 0.124 & 0.566 & 0.001 \\
\hline & $\begin{array}{l}\text { Reasonable amount of direct clerical tasks (Q10a) } \\
(0=\text { disagree/neutral, } 1 \text { = agree) }\end{array}$ & 0.469 & 0.289 & 0.761 & 0.002 \\
\hline & Effective support staff (Q11) (0 = too little, 1 = about right) & 0.513 & 0.347 & 0.758 & 0.001 \\
\hline & No. of outpatients (Q15) & 1.011 & 1.003 & 1.018 & 0.004 \\
\hline & Age (Q19) & 0.958 & 0.941 & 0.975 & $<0.001$ \\
\hline & Epilepsy (Q24) (compared to general neurology) & 0.408 & 0.166 & 0.999 & 0.050 \\
\hline
\end{tabular}

Abbreviations: $\mathrm{Cl}=$ confidence interval; $\mathrm{OR}=$ odds ratio.

Three multivariable analyses were conducted to identify personal and professional factors associated with burnout. The first model included all neurologists. Given substantial differences in professional characteristics, separate models were also created for academic practice neurologists and clinical practice neurologists.

${ }^{\text {a }}$ Personal characteristics in all models: age, sex, region.

${ }^{b}$ Professional characteristics in all models: autonomy, meaningful work, direct clerical tasks, indirect clerical tasks, effective support staff, hours per week, nights on call, number of outpatients, number of inpatients, number of weekends hospital rounding, subspecialty.

${ }^{\mathrm{c}}$ Additional professional characteristics all neurologist model: \% clinical time, academic vs clinical work setting, employment status, compensation method.

${ }^{\mathrm{d}}$ Results shown when variable was significant in all 3 variable entry methods (all at once, forward stepwise, and backward stepwise). Some variables were significant in only 1 or 2 of the methods: \% clinical time, region, and behavioral neurology.

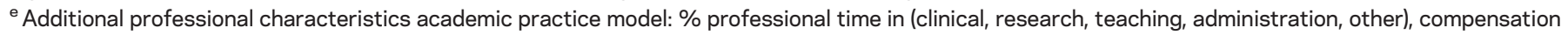
method (salary vs salary plus bonus).

${ }^{f}$ Results shown when variable was significant in all 3 variable entry methods (all at once, forward stepwise, and backward stepwise). Some variables were significant in only 1 or 2 of the methods: direct and indirect clerical tasks, nights on call, region, child neurology, epilepsy, and sleep medicine.

${ }^{9}$ Additional professional characteristics clinical practice model: \% clinical time, practice setting (solo, neurology group, multispecialty group, hospital), employment status, compensation method.

${ }^{h}$ Results shown when variable was significant in all 3 variable entry methods (all at once, forward stepwise, and backward stepwise). One additional variable was significant in 2 of the methods: nights on call.

and points towards some potential explanations. Although epilepsy subspecialization was associated with lower burnout risk and sleep subspecialization was associated with less profession satisfaction, neurologists are experiencing greater struggles with drivers experienced by all physicians. ${ }^{13,19}$ Neurologists work 55 median hours per week compared to 50 for all US physicians. Only $32.3 \%$ of neurologists indicated their work schedule leaves enough time for personal/ family life compared to $40.9 \%$ of all physicians, a rate lower than every other medical specialty. ${ }^{19}$ Only $23.0 \%$ of neurologists were satisfied with time spent on clerical tasks directly related to patient care compared to $37.2 \%$ of all physicians, a rate lower than every other medical specialty except family practice. ${ }^{29}$ Similarly, only $15.9 \%$ of neurologists were satisfied with time spent on clerical tasks indirectly related to patient care, compared to $25.6 \%$ of all physicians. ${ }^{29}$ Neurologists' mean overall QOL score was 6.2 with $34 \%$ scoring $<6$ compared to a mean of 7.4 with $28 \%$ scoring $<6$ for all physicians (personal communication, 2016, Tait Shanafelt).

Neurologists' profession satisfaction was also lower than that of physicians in other specialties. ${ }^{19}$ Overall, 
Table 5 Factors associated with profession satisfaction using multivariable analyses

\begin{tabular}{|c|c|c|c|c|}
\hline \multirow[b]{2}{*}{ Predictor $^{a-c}$} & \multirow[b]{2}{*}{ OR } & \multicolumn{2}{|c|}{$95 \% \mathrm{Cl}$} & \multirow[b]{2}{*}{$p$ Value } \\
\hline & & Lower & Upper & \\
\hline Burnout $^{d}$ & 0.357 & 0.253 & 0.505 & $<0.001$ \\
\hline Autonomy in job (Q9a) (0 = disagree/neutral, 1 = agree) & 2.113 & 1.543 & 2.893 & $<0.001$ \\
\hline Meaningful work (Q9b) (0 = disagree/neutral, 1 = agree) & 3.068 & 2.027 & 4.644 & $<0.001$ \\
\hline Effective support staff (Q11) $(0=$ too little, 1 = about right $)$ & 1.464 & 1.062 & 2.019 & 0.020 \\
\hline \% Time in clinical practice (Q13_1) & 0.988 & 0.979 & 0.996 & 0.005 \\
\hline Age (Q19) & 1.027 & 1.012 & 1.041 & $<0.001$ \\
\hline Sleep medicine (Q24) (compared to general neurology) & 0.300 & 0.138 & 0.650 & 0.002 \\
\hline
\end{tabular}

Abbreviations: $\mathrm{Cl}=$ confidence interval; $\mathrm{OR}=$ odds ratio.

Multivariable analyses were conducted to identify personal and professional factors associated with becoming a neurologist again.

${ }^{\text {a }}$ Results shown when variable was significant in all 3 variable entry methods (all at once, forward stepwise, and backward stepwise).

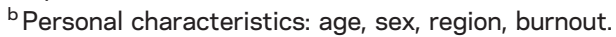

c Professional characteristics: autonomy, meaningful work, direct clerical tasks, indirect clerical tasks, effective support staff, hours per week, nights on call, number of outpatients, number of inpatients, number of weekends hospital rounding, subspecialty, \% clinical time, academic vs clinical work setting, employment status, compensation method.

${ }^{\mathrm{d}}$ High score on Emotional exhaustion or depersonalization subscales of the Maslach Burnout Inventory (see Methods).

$61.3 \%$ of neurologists would become a physician again, compared to $67 \%$ of all physicians. If they could revisit their specialty choice, $67.2 \%$ would become a neurologist again, compared to $70.8 \%$ of all physicians. Neurologists' lower career and specialty satisfaction is consistent with their higher burnout rate and lower work-life balance; however, this pattern is not observed in other specialties. For example, medical oncologists have markedly higher rates of career and specialty satisfaction than neurologists but have average burnout rates and very low rates of satisfaction with work-life balance. ${ }^{26,31}$

Engagement, a persistent positive state of fulfillment characterized by vigor, dedication, and absorption, is the inverse of burnout. ${ }^{18,32-35}$ Promoting engagement may lower burnout risk. Individual, work unit, organization, and national factors can influence burnout and engagement. ${ }^{8,29}$ Strategies to mitigate burnout and increase engagement can be aimed at each of these levels. ${ }^{8,29}$

Our study is subject to several limitations. Although our response rate of $\sim 40 \%$ is consistent with $^{36}$ or higher ${ }^{19,37}$ than physician surveys in general, and we found no significant differences among early responders compared to late responders with respect to age, sex, practice setting, geographic region, or burnout, response bias remains possible. Because the survey was cross-sectional, we were unable to determine causality or potential direction of effect for the associations observed. Distinctions between AP and CP settings may have been blurred because AP and CP definitions were ambiguous, given the wide variety of current AP models. Some respondents working in academic settings may have designated themselves as $\mathrm{CP}$.

Our study has important strengths. Our mixedmethods survey design led to a high participation rate relative to other national studies of physicians. The neurologists in the sample were drawn from the AAN member database, a list comprising most US neurologists. The survey included neurologists with a wide range of personal and practice characteristics. The extensive information collected on these characteristics enabled detailed insights into relationships among these factors and burnout, career satisfaction, and well-being for most neurologists.

Our results provide a high-level overview of factors associated with increased burnout, decreased career satisfaction, and well-being in neurologists and why neurology fares poorly compared to other specialties, but are insufficient to determine all the underlying reasons. One can speculate that personality traits of those who choose neurology ${ }^{3}$; the time-consuming and meticulous nature of neurologic assessment; and the intellectual, emotional, and physical devastation associated with many neurologic illnesses may play important roles, ${ }^{20-22}$ but additional studies are needed to assess these hypotheses. Qualitative analysis of the free text comments many respondents contributed to our survey may provide some insights.

Excessive workload (i.e., hours and patient volume), loss of autonomy, clerical burden, and inadequate support staff are associated with the high prevalence of burnout and low rates of satisfaction with career and work-life integration among US neurologists. Effective approaches to address these issues and 
cultivate meaning and engagement in neurology practice could include efforts within the work unit and organization to improve efficiency, optimize workload, decrease clerical burden, provide greater flexibility and control over work, and enhance support staff. ${ }^{38}$ Physician-friendly national policies that decrease regulatory burden and mandated clerical tasks would also enhance neurologists' engagement in the practice of neurology. ${ }^{22,39}$ Studies testing strategies to achieve these goals will likely foster more rapid dissemination of best practices. ${ }^{40}$

\section{AUTHOR CONTRIBUTIONS}

Neil A. Busis: design of the study, interpretation of the data, drafting and revising the manuscript for intellectual content. Tait D. Shanafelt: design of the study, interpretation of the data, drafting and revising the manuscript for intellectual content. Christopher M. Keran: design of the study, analysis and interpretation of the data, drafting and revising the manuscript for intellectual content. Kerry H. Levin: design of the study, interpretation of the data, revising the manuscript for intellectual content. Heidi B. Schwarz: design of the study, drafting and revising the manuscript for intellectual content. Jennifer R. Molano: design of the study, drafting and revising the manuscript for intellectual content. Thomas R. Vidic: design of the study, drafting and revising the manuscript for intellectual content. Joseph S. Kass: drafting the manuscript for intellectual content. Janis M. Miyasaki: drafting and revising the manuscript for intellectual content. Jeff A. Sloan: design of the study, interpretation of the data. Terrence L. Cascino: conceptualization of the study, commenting on manuscript for intellectual content.

\section{ACKNOWLEDGMENT}

The authors thank the AAN Burnout Task Force for assistance in designing the study, comments on the survey instrument, and pilot testing the survey instrument: Bruce T. Adornato, MD; Sarah Benish, MD; Neil A. Busis, MD; Terrence L. Cascino, MD (Chair); Patricia K. Crumrine, MD; Aviva Ellenstein, MD, PhD; Blair Ford, MD; Laura A. Foster, MD; William David Freeman, MD; Shafali Jeste, MD; Elaine C. Jones, MD; Joseph S. Kass, MD, JD; Richard A. Lafrance, MD; Laura Lennihan, MD; Kerry H. Levin, MD; Kenneth J. Mack, MD, PhD; Jennifer Molano, MD; Cormac A. O’Donovan, MD; Heidi B. Schwarz, MD (Co-chair); Lisa M. Shulman, MD; Bruce Sigsbee, MD; and Thomas R. Vidic, MD. The authors thank these individuals for pilot testing and providing comments on the survey instrument: Clinton E. Branch, Jr., MD; David Capobianco, MD; Diana Goodman, MD; J. Clay Goodman, MD; Victor W. Henderson, MD; Donald Iverson, MD; Ralph Jozefowicz, MD; Monica Koehn, MD; Jeffrey McClean II, MD; Massimo Pandolfo, MD; Noor A. Pirzada, MD; Benn E. Smith, MD; Ann H. Tilton, MD; and Bert Vargas, MD. The authors also thank these individuals for proofreading the survey instrument and manuscript: Nellie Adams and Carolyn Cahill; and for proofreading the manuscript and references: Lisa Gulya.

\section{STUDY FUNDING}

Study funded by the American Academy of Neurology.

\section{DISCLOSURE}

N. Busis receives honoraria for speaking at American Academy of Neurology courses and for serving as Alternate CPT Advisor for American Academy of Neurology and is a member of the American Academy of Neurology Board of Directors. T. Shanafelt reports no disclosures. C. Keran is an employee of the American Academy of Neurology. K. Levin receives honoraria from the American Academy of Neurology and American Board of Psychiatry and Neurology and royalties from UpToDate and Elsevier. H. Schwarz is a member of the American Academy of Neurology Board of Directors. J. Molano serves on the Neurology Now and NEJM Journal Watch Neurology Editorial Advisory Boards. T. Vidic is a member of the American Academy of Neurology Board of Directors.
J. Kass is a member of the Continuum Editorial Board. J. Miyasaki receives grants through PCORI and Parkinson Alberta and is a member of the American Academy of Neurology Board of Directors. J. Sloan reports no disclosures. T. Cascino serves as President of the American Academy of Neurology. Go to Neurology.org for full disclosures.

Received August 31, 2016. Accepted in final form October 27, 2016.

\section{REFERENCES}

1. Bodenheimer T, Sinsky C. From triple to quadruple aim: care of the patient requires care of the provider. Ann Fam Med 2014;12:573-576.

2. Dyrbye LN, Shanafelt TD. Physician burnout: a potential threat to successful health care reform. JAMA 2011;305: 2009-2010.

3. Wallace JE, Lemaire JB, Ghali WA. Physician wellness: a missing quality indicator. Lancet 2009;374:1714-1721.

4. Maslach C, Jackson S, Leiter M. Maslach Burnout Inventory Manual. 3rd ed. Palo Alto, CA: Consulting Psychologists Press; 1996.

5. Firth-Cozens J, Greenhalgh J. Doctors' perceptions of the links between stress and lowered clinical care. Soc Sci Med 1997;44:1017-1022.

6. Shanafelt TD, Balch CM, Bechamps G, et al. Burnout and medical errors among American surgeons. Ann Surg 2010; 251:995-1000.

7. Shanafelt T, Sloan J, Satele D, Balch C. Why do surgeons consider leaving practice? J Am Coll Surg 2011;212:421-422.

8. Shanafelt TD, Mungo M, Schmitgen J, et al. Longitudinal study evaluating the association between physician burnout and changes in professional work effort. Mayo Clin Proc 2016;91:422-431.

9. Landon BE, Reschovsky JD, Pham HH, Blumenthal D. Leaving medicine: the consequences of physician dissatisfaction. Med Care 2006;44:234-242.

10. Sibbald B, Bojke C, Gravelle H. National survey of job satisfaction and retirement intentions among general practitioners in England. BMJ 2003;326:22-25.

11. Shanafelt TD, Balch CM, Dyrbye L, et al. Special report: suicidal ideation among American surgeons. Arch Surg 2011;146:54-62.

12. Center C, Davis M, Detre T, et al. Confronting depression and suicide in physicians: a consensus statement. JAMA 2003;289:3161-3166.

13. Shanafelt TD, Boone S, Tan L, et al. Burnout and satisfaction with work-life balance among US physicians relative to the general US population. Arch Intern Med 2012; 172:1377-1385.

14. Oreskovich MR, Shanafelt T, Dyrbye LN, et al. The prevalence of substance use disorders in American physicians. Am J Addict 2015;24:30-38.

15. Dyrbye LN, Sotile W, Boone S, et al. A survey of U.S. physicians and their partners regarding the impact of work-home conflict. J Gen Intern Med 2014;29:155-161.

16. Dyrbye LN, Freischlag J, Kaups KL, et al. Work-home conflicts have a substantial impact on career decisions that affect the adequacy of the surgical workforce. Arch Surg 2012;147:933-939.

17. Gold KJ, Sen A, Schwenk TL. Details on suicide among US physicians: data from the national violent death reporting system. Gen Hosp Psychiatry 2013;35:45-49.

18. Maslach C, Leiter MP. Understanding the burnout experience: recent research and its implications for psychiatry. World Psychiatry 2016;15:103-111. 
19. Shanafelt TD, Hasan O, Dyrbye LN, et al. Changes in burnout and satisfaction with work-life balance in physicians and the general US working population between 2011 and 2014. Mayo Clin Proc 2015;90:1600-1613.

20. Sigsbee B, Bernat JL. Physician burnout: a neurologic crisis. Neurology 2014;83:2302-2306.

21. Freeman WD, Vatz KA, Griggs RC, Pedley T. The Workforce Task Force report: clinical implications for neurology. Neurology 2013;81:479-486.

22. Busis NA. To revitalize neurology we need to address physician burnout. Neurology 2014;83:2202-2203.

23. Dyrbye LN, West CP, Shanafelt TD. Defining burnout as a dichotomous variable. J Gen Intern Med 2009;24:440; author reply 441 .

24. Frank E, McMurray JE, Linzer M, Elon L. Career satisfaction of US women physicians: results from the Women Physicians' Health Study: Society of General Internal Medicine Career Satisfaction Study Group. Arch Intern Med 1999;159:1417-1426.

25. Lemkau J, Rafferty J, Gordon R Jr. Burnout and careerchoice regret among family practice physicians in early practice. Fam Pract Res J 1994;14:213-222.

26. Shanafelt TD, Gradishar WJ, Kosty M, et al. Burnout and career satisfaction among US oncologists. J Clin Oncol 2014;32:678-686.

27. Spreitzer GM. Psychological empowerment in the workplace: dimensions, measurement, and validation. Acad Manage J 1995;38:1442-1465.

28. Williams ES, Konrad TR, Linzer M, et al. SGIM career satisfaction study group. Refining the measurement of physician job satisfaction: results from the physician worklife survey. Med Care 1999;37:1140-1154.

29. Shanafelt TD, Dyrbye LN, Sinsky C, et al. Relationship between clerical burden and characteristics of the electronic environment with physician burnout and professional satisfaction. Mayo Clin Proc 2016;91:836-848.
30. Singh JA, Satele D, Pattabasavaiah S, Buckner JC, Sloan JA. Normative data and clinically significant effect sizes for single-item numerical linear analogue self-assessment (LASA) scales. Health Qual Life Outcomes 2014;12:187.

31. Shanafelt TD, Raymond M, Kosty M, et al. Satisfaction with work-life balance and the career and retirement plans of US oncologists. J Clin Oncol 2014;32:1127-1135.

32. Schaufeli WB, Salanova M, Gonzalez-Roma V, Bakker AB. The measurement of engagement and burnout: a two sample confirmatory factor analytic approach. J Happiness Stud 2002;3:71-92.

33. Schaufeli WB, Bakker AB, Salanova M. The measurement of work engagement with a short questionnaire: a crossnational study. Educ Psychol Meas 2006;66:701-716.

34. Shimazu A, Schaufeli WB. Work engagement: an emerging concept in occupational health psychology. Biosci Trends 2008;2:2.

35. Durán A, Extremera N, Rey L. Engagement and burnout: analysing their association patterns. Psychol Rep 2004;94: 1048-1050.

36. Asch DA, Jedrziewski MK, Christakis NA. Response rates to mail surveys published in medical journals. J Clin Epidemiol 1997;50:1129-1136.

37. Shanafelt TD, Balch CM, Bechamps GJ, et al. Burnout and career satisfaction among American surgeons. Ann Surg 2009;250:463-471.

38. Shanafelt TD, Gorringe G, Menaker R, et al. Impact of organizational leadership on physician burnout and satisfaction. Mayo Clin Proc 2015;90:432-440.

39. Ringel SP. The practice of neurology: looking ahead by looking back. Neurology 2015;84:2086-2091.

40. West CP, Dyrbye LN, Erwin P, Shanafelt TD. Interventions to prevent and reduce physician burnout: a systematic review and meta-analysis. Lancet 2016; 388:2272-2281.

\section{Minutes Pack a Punch}

\section{Neurology ${ }^{\circledR}$ Podcasts}

- Interviews with top experts on new clinical research in neurology

- Editorial comments on selected articles

- Convenient-listen during your commute, at your desk, or even at the gym

- On demand-it's there when you want it

- Fun and engaging

- New topic each week

- FREE

Listen now at www.aan.com/podcast 


\section{Neurology}

\section{Burnout, career satisfaction, and well-being among US neurologists in 2016 \\ Neil A. Busis, Tait D. Shanafelt, Christopher M. Keran, et al.}

Neurology 2017;88;797-808 Published Online before print January 25, 2017

DOI 10.1212/WNL.0000000000003640

\section{This information is current as of January 25, 2017}

$\begin{array}{ll}\begin{array}{l}\text { Updated Information \& } \\ \text { Services }\end{array} & \begin{array}{l}\text { including high resolution figures, can be found at: } \\ \text { http://n.neurology.org/content/88/8/797.full }\end{array} \\ \text { Supplementary Material } & \text { Supplementary material can be found at: } \\ \text { http://n.neurology.org/content/supp1/2017/01/26/WNL.0000000000003 } & \text { 640.DC1 } \\ \text { http://n.neurology.org/content/supp1/2017/02/21/WNL.0000000000003 } & \text { 640.DC2 } \\ \text { http://n.neurology.org/content/supp1/2018/03/27/WNL.0000000000003 } \\ \\ 640 . D C 3\end{array}$

Neurology ${ }^{\circledR}$ is the official journal of the American Academy of Neurology. Published continuously since 1951, it is now a weekly with 48 issues per year. Copyright @ 2017 American Academy of Neurology. All rights reserved. Print ISSN: 0028-3878. Online ISSN: 1526-632X.

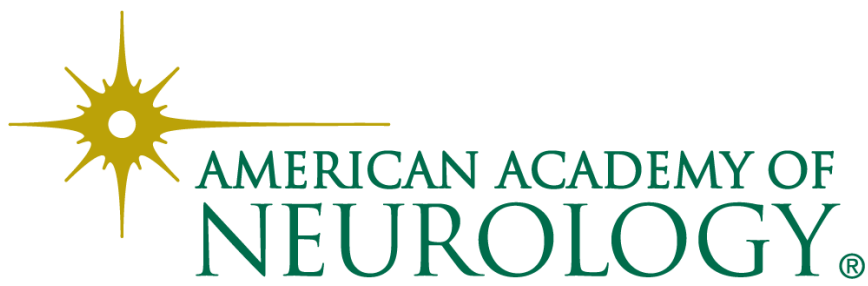

